\title{
Pengaruh Waktu Inkubasi Kapur dan Abu Sekam Terhadap Perubahan Beberapa Sifat Kimia Ultisol
}

\section{The Effect of Incubation Time of Calcium and Husk Ash on Changes in Some Chemical Properties of Ultisol}

\author{
Wirza Emaliana $^{1}$, Munawar Khalil ${ }^{1}$, Ilyas ${ }^{1 *}$ \\ ${ }^{1}$ Program Studi Ilmu Tanah, Fakultas Pertanian, Universitas Syiah Kuala \\ Email: wirzaemaliana14@gmail.com
}

\begin{abstract}
Abstrak. Penelitian ini bertujuan untuk melihat pengaruh waktu inkubasi kapur dan abu sekam terhadap perubahan beberapa sifat kimia Ultisol dengan menggunakan Rancangan Acak Lengkap (RAL) non faktorial yang dilakukan pada tanah yang sama, dengan 2 bahan yang berbeda yaitu kapur dan abu sekam. Dosis diberikan sebanyak 4 taraf dan diulang 4 kali sehingga terdapat 8 perlakuan dan 32 satuan percobaan dengan waktu inkubasi selama 2, 4 dan 6 minggu. Untuk melihat perbedaan hasil perlakuan digunakan uji $\mathrm{F}$ dan dilanjutkan dengan uji $\left(\mathrm{BNT}_{0,05}\right)$. Hasil penelitian menunjukkan bahwa semakin lama inkubasi kapur dan abu sekam maka kemasaman tanah $(\mathrm{pH})$, Kapasitas Tukar Kation (KTK), P-tersedia semakin meningkat dan Al-dd semakin menurun. Inkubasi 6 minggu merupakan waktu yang tepat untuk menaikkan $\mathrm{pH}$, KTK dan meningkatkan Ptersedia, kecuali pada $\mathrm{pH}$ pemberian abu sekam waktu yang tepat adalah inkubasi 4 minggu. Sedangkan Al-dd pada inkubasi 2 minggu kapur dan abu sekam sudah hilang dan tak terukur. Dapat disimpulkan bahwa, kapur dolomit dan abu sekam pada Ultisol memberikan perbedaan yang sangat nyata pada $\mathrm{pH}$, P-tersedia, KTK dan Al-dd.
\end{abstract}

Kata kunci : kapur, abu sekam, sifat kimia, Ultisol.

\begin{abstract}
This study aims to examine the effect of incubation time of calcium and husk ash on changes in some chemical properties of Ultisol by using a non-factorial Completely Randomized Design (RAL) performed on the same soil, with 2 different materials which were calcium and husk ash. The dose was given 4 levels and repeated 4 times so that there were 8 treatments and 32 experimental units with incubation time for 2, 4 and 6 weeks. To see the differences of treatment result, F test continued with test (BNT0,05) were used. The results showed that the longer incubation of calsium and husk ash acidity $(\mathrm{pH})$, Cation Exchange Capacity (CEC) and P-available increased and Al-dd decreased. The 6 weeks incubation was the exact time to increase $\mathrm{pH}, \mathrm{CEC}$ and increase $\mathrm{P}$ available, except the exact time for $\mathrm{pH}$ of husk ash, i.e which was 4 weeks incubation. While Al-dd on 2 weeks incubation, calcium and husk ash had been disappeared and immeasurable. It can be concluded that dolomite calcium and husk ash on Ultisol showed a very significant difference in $\mathrm{pH}, \mathrm{P}$-available, CEC and Al-dd.
\end{abstract}

Keyword : calcium, husk ash, chemical properties, Ultisol

\section{PENDAHULUAN}

Ultisol merupakan tanah yang mempunyai tingkat perkembangan yang cukup lanjut, mempunyai ciri penampang tanah yang dalam, kenaikan fraksi liat seiring dengan kedalaman tanah, reaksi tanah masam, kejenuhan basa rendah, miskin kandungan hara terutama $\mathrm{P}$ dan kation-kation dapat ditukar seperti $\mathrm{Ca}, \mathrm{Mg}, \mathrm{Na}$, dan $\mathrm{K}$, kadar $\mathrm{Al}$ tinggi, kapasitas tukar kation rendah dan peka terhadap erosi. Pada umumnya, Ultisol mempunyai potensi keracunan Al dan miskin kandungan bahan organik (Sri Adiningsih dan Mulyadi, 1993).

Berdasarkan permasalahan Ultisol tersebut, maka salah satu alternatif yang dapat dilakukan untuk mengatasi masalah diatas adalah dengan pengapuran. Pengapuran dapat meningkatkan $\mathrm{pH}$ tanah, menambahkan unsur yang mengandung $\mathrm{Ca}$ ke dalam tanah, mengurangi resiko keracunan aluminium, menambah ketersediaan unsur hara $\mathrm{P}$ sebagai hasil pembebasan $\mathrm{P}$ dari ikatan Al-P dan Fe-P, meningkatkan KTK, meningkatkan fiksasi $\mathrm{N}$ dan mineralisasi $\mathrm{N}$ serta membantu penyempurnaan perombakan dengan disertai pelepasan hara dari bahan-bahan organik dan tubuh mikroba (Kuswandi, 1993). 
Alternatif lain untuk memperbaiki sifat-sifat kimia tanah Ultisol dan mengupayakan $\mathrm{P}$ menjadi tersedia dalam tanah adalah dengan pemberian abu sekam padi. Sekam padi merupakan salah satu limbah pertanian, sekam padi yang banyak tersedia belum banyak dimanfaatkan secara efisien (Susanti, 1994). Sekam padi ini merupakan salah satu sumber bahan organik yang mudah tersedia, namun perlu diketahui manfaat yang terkandung didalamnya. Abu sekam padi sebagai sumber silikat (Si) dapat melepaskan $\mathrm{P}$ terjerap dan mencegah terjadinya fiksasi P. Silikat merupakan salah satu anion penentu potensial yang dapat berkompetisi dalam menduduki kompleks jerapan. Oleh karena itu, sifat kompetisi ini dapat dimanfaatkan untuk meningkatkan ketersediaan P (Mengel et al., 1987).

Abu sekam padi mengandung beberapa unsur hara selain silikat, yaitu $\mathrm{P} 0,20 \%$; $\mathrm{K}$ 1,21\%; Ca dan Mg (me/100 g) 0,26 dan 0,12 (Raihan et al., 2005). Kandungan Kalium dan Fosfor alam yang terkandung pada abu sekam padi mampu meningkatkan KTK, menaikkan $\mathrm{pH}$, membantu dalam ketersediaan $\mathrm{K}, \mathrm{P}, \mathrm{Mg}$ serta bahan organik.

\section{METODE PENELITIAN}

Penelitian ini dilakukan dengan pengambilan bahan tanah Ultisol di Jantho Kabupaten Aceh Besar. Inkubasi dan analisis sifat kimia tanah dilakukan di Laboratorium Penelitian Tanah dan Tanaman Fakultas Pertanian, Universitas Syiah Kuala Darussalam Banda Aceh serta Balai Riset dan Standardisasi (Baristand) Industri Aceh.

\section{MATERI DAN METODE}

Bahan tanah Ultisol yang berasal dari Jantho, Kabupaten Aceh Besar, kapur dolomit, abu sekam padi dan sejumlah bahan kimia diantaranya aquades dan pengekstray Bray yang berasal dari Laboratorium Penelitian Tanah dan Tanaman Fakultas Pertanian Universitas Syiah Kuala, Darussalam Banda Aceh serta Balai Riset dan Standardisasi (Baristand) Industri Aceh.

\section{Metode Penelitian}

\section{Analisis Statistik}

Penelitian ini menggunakan Rancangan Acak Lengkap (RAL) non faktorial yang dilakukan pada tanah yang sama, dengan 2 bahan yang berbeda yaitu kapur dan abu sekam. Dosis yang diberikan sebanyak 4 taraf dengan pengulangan sebanyak 4 kali sehingga didapat 8 kali perlakuan dan 32 kali satuan percobaan untuk semua inkubasi dengan masa inkubasi selama 2, 4 dan 6 minggu.

\section{Pelaksanaan Penelitian}

\section{Penyiapan Tanah, Kapur dan Abu Sekam}

Permukaan tanah dibersihkan dari serasah tanaman, kemudian bahan tanah diambil dengan menggunakan cangkul pada tanah lapisan atas (top soil) dengan kedalaman berkisar antara 0-20 cm. Bahan tanah tersebut dikeringanginkan dan dihancurkan serta diayak dengan ayakan yang berukuran diameter lubang $2 \mathrm{~mm}$ kemudian dilakukan analisis awal beberapa sifat kimia tanah. Kapur yang digunakan adalah dolomit, dengan bahan yang terkandung di dalamnya $\mathrm{CaO}$ sebesar $\pm 30 \%$ dan $\mathrm{MgO}$ sebesar $\pm 18-21 \%$. Sedangkan analisis abu sekam dilakukan untuk mengetahui kandungan silikat $\left(\mathrm{SiO}_{2}\right)$. 


\section{Pelaksanaan Kegiatan}

Bahan tanah Ultisol dimasukkan kedalam polibag sebanyak $1 \mathrm{~kg}$ untuk 8 polibag, dimana 4 polibag untuk pemberian kapur dan 4 polibag lainnya untuk pemberian abu sekam. Diberikan kapur dolomit sebanyak 4 ton/ha atau setara dengan $2 \mathrm{~g}$ kapur/1 kg tanah, 6 ton/ha atau setara dengan $3 \mathrm{~g}$ kapur/1 $\mathrm{kg}$ tanah, 8 ton/ha atau setara dengan $4 \mathrm{~g}$ kapur/1 $\mathrm{kg}$ tanah dan 10 ton/ha atau setara dengan $5 \mathrm{~g}$ kapur/1 $\mathrm{kg}$ tanah untuk 4 polibag. Sedangkan untuk 4 polibag lainnya diberikan abu sekam sebanyak 10 ton/ha atau setara dengan $5 \mathrm{~g}$ abu sekam/1 kg tanah, $15 \mathrm{ton} / \mathrm{ha}$ atau setara dengan 7,5 g abu sekam/1 kg tanah, 20 ton/ha atau setara dengan $10 \mathrm{~g}$ abu sekam/1 kg tanah, dan 25 ton/ha atau setara dengan 12,5 g abu sekam/1 kg tanah. Kemudian diinkubasi selama 6 minggu dengan interval pengamatan setiap 2 minggu sekali. Kondisi tanah dipertahankan dalam kondisi kapasitas lapang.

\section{Pengamatan}

Parameter sifat kimia tanah yang diamati di laboratorium adalah $\mathrm{pH}$ tanah, P-tersedia, Al-dd dan KTK.

\section{HASIL DAN PEMBAHASAN}

\section{Kapur pH Tanah}

Hasil analisis $\mathrm{pH}$ pada tanah yang telah diberikan kapur dan diinkubasi dengan waktu dan dosis yang berbeda-beda selama 2, 4 dan 6 minggu. Hasil uji F pada Tabel analisis sidik ragam menunjukkan bahwa pemberian kapur berpengaruh terhadap $\mathrm{pH}$. Rata-rata $\mathrm{pH}$ tanah setelah pemberian kapur yang diinkubasi dalam waktu tertentu disajikan pada Tabel 6.

Tabel 6. Rata-rata $\mathrm{pH}$ tanah setelah pemberian kapur dalam waktu 2, 4 dan 6 minggu

\begin{tabular}{cccc}
\hline \multirow{2}{*}{ Perlakuan } & \multicolumn{3}{c}{ Waktu Inkubasi } \\
\cline { 2 - 4 } & 2 Minggu & 4 Minggu & 6 Minggu \\
\hline K1 $(2 \mathrm{~g})$ & $6,37(\mathrm{ab})$ & $6,44(\mathrm{~b})$ & $6,20(\mathrm{a})$ \\
K2 $(3 \mathrm{~g})$ & $6,34(\mathrm{a})$ & $6,34(\mathrm{a})$ & $7,07(\mathrm{~d})$ \\
K3 $(4 \mathrm{~g})$ & $6,43(\mathrm{~b})$ & $6,47(\mathrm{~b})$ & $6,76(\mathrm{~b})$ \\
K4 $(5 \mathrm{~g})$ & $6,52(\mathrm{c})$ & $6,58(\mathrm{c})$ & $6,91(\mathrm{c})$ \\
\hline BNT 0,05 & 0,06 & 0,08 & 0,08 \\
\hline
\end{tabular}

Keterangan: Angka rata-rata yang diikuti oleh huruf yang sama tidak berbeda nyata pada uji BNT 0,05

Berdasarkan uji $\mathrm{F}$, terlihat bahwa pemberian kapur setelah 2, 4 dan 6 minggu inkubasi menunjukkan perbedaan yang sangat nyata terhadap nilai $\mathrm{pH}$. Kemasaman $(\mathrm{pH})$ tertinggi akibat pemberian kapur 2 minggu terdapat pada dosis 5 g yaitu 6,52. Kemasaman $(\mathrm{pH})$ meningkat sebesar 1,17 dari $\mathrm{pH}$ awal $(5,35)$ dan yang terendah pada dosis 3 g yaitu 6,34, tetapi masih meningkat dibandingkan $\mathrm{pH}$ awal yaitu sebesar 0,99 . Sedangkan pada inkubasi 4 minggu setelah pemberian kapur $\mathrm{pH}$ tertinggi terdapat pada dosis $5 \mathrm{~g}$ yaitu 6,58. Kemasaman $(\mathrm{pH})$ meningkat sebesar 1,23 dari $\mathrm{pH}$ awal dan yang terendah terlihat pada dosis $3 \mathrm{~g}$ yaitu 6,34 dan masih meningkat dibandingkan dengan $\mathrm{pH}$ awal yaitu sebesar 0,99. Pemberian kapur yang diinkubasi selama 6 minggu menunjukkan $\mathrm{pH}$ tertinggi pada dosis 3 g yaitu 7,07. Kemasaman $(\mathrm{pH})$ meningkat sebesar 1,72 dari $\mathrm{pH}$ awal dan yang terendah dapat terlihat pada dosis $2 \mathrm{~g}$ yaitu 6,20, tetapi masih meningkat dibandingkan $\mathrm{pH}$ awal yaitu sebesar 0,85 .

Meningkatnya $\mathrm{pH}$ akibat pemberian kapur dikarenakan terjadi penetralan ion $\mathrm{H}^{+}$oleh kapur. Kapur mengandung kation-kation basa seperti $\mathrm{Ca}$ dan $\mathrm{Mg}$ sehingga kapur dapat menyumbang kation-kation basa pada tanah. Hal ini, sesuai dengan pernyataan Hardjowigeno 
(1992), kapur juga merupakan bahan yang mengandung unsur Ca yang dapat meningkatkan $\mathrm{pH}$ tanah.

Iqbal (2011) menyatakan bahwa, pemberian kapur menyebabkan terjadinya penetralan ion $\mathrm{H}^{+}$oleh ion $\mathrm{CO}_{3}{ }^{2-}$ yang berasal dari bahan kapur, dengan makin tinggi takaran pemberian kapur maka semakin banyak pula ion $\mathrm{H}^{+}$yang dinetralkan sehingga $\mathrm{pH}$ tanah menjadi meningkat. Selain itu, meningkatnya $\mathrm{pH}$ tanah akibat pengapuran dapat disebabkan oleh penambahan ion $\mathrm{OH}^{-}$hasil hidrolisasi bahan kapur yang ditambahkan, sehingga semakin banyak $\mathrm{OH}^{-}$dalam tanah maka $\mathrm{pH}$ akan meningkat. Kussow (1971) dalam Iqbal (2011) mengemukakan bahwa penetral pada tanah masam adalah ion $\mathrm{CO}_{3}{ }^{2-}$ karena dapat menggantikan ion $\mathrm{H}^{+}$pada kompleks pertukaran tanah. Karena terjadi pertukaran ini, maka potensial muatan negatif tanah meningkat sehingga kemampuan tanah untuk menjerap basabasa menjadi lebih besar.

Oleh karena itu, semakin lama inkubasi kapur maka pH semakin netral. Waktu inkubasi 6 minggu merupakan waktu paling tepat untuk menaikkan $\mathrm{pH}$ menjadi netral, tetapi jika tanaman menghendaki $\mathrm{pH}$ yang tidak terlalu netral atau agak masam maka pada inkubasi 2 atau 4 minggu sangat dianjurkan.

\section{P-tersedia}

Hasil analisis P-tersedia pada tanah yang telah diberikan kapur dan diinkubasi dengan waktu dan dosis yang berbeda-beda selama 2, 4 dan 6 minggu. Hasil uji F pada Tabel analisis sidik ragam menunjukkan bahwa pemberian kapur berpengaruh terhadap P-tersedia. Rata-rata P-tersedia tanah setelah pemberian kapur yang diinkubasi dalam waktu tertentu disajikan pada Tabel 7.

Tabel 7. Rata-rata P-tersedia $\left(\mathrm{mg} \mathrm{kg}^{-1}\right)$ tanah setelah pemberian kapur dalam waktu 2, 4 dan 6 minggu

\begin{tabular}{cccc}
\hline \multirow{2}{*}{ Perlakuan } & \multicolumn{3}{c}{ Waktu Inkubasi } \\
\cline { 2 - 4 } & 2 Minggu & 4 Minggu & 6 Minggu \\
\hline K1 $(2 \mathrm{~g})$ & $2,80(\mathrm{~d})$ & $2,29(\mathrm{a})$ & $2,80(\mathrm{a})$ \\
K2 $(3 \mathrm{~g})$ & $2,08(\mathrm{a})$ & $2,62(\mathrm{~b})$ & $3,14(\mathrm{~b})$ \\
K3 $(4 \mathrm{~g})$ & $2,58(\mathrm{c})$ & $2,80(\mathrm{~b})$ & $3,53(\mathrm{c})$ \\
K4 $(5 \mathrm{~g})$ & $2,31(\mathrm{~b})$ & $2,38(\mathrm{a})$ & $2,86(\mathrm{a})$ \\
\hline BNT 0,05 & 0,19 & 0,23 & 0,24 \\
\hline
\end{tabular}

Keterangan: Angka rata-rata yang diikuti oleh huruf yang sama tidak berbeda nyata pada uji BNT 0,05

Berdasarkan uji $\mathrm{F}$, terlihat bahwa pemberian kapur setelah 2, 4 dan 6 minggu inkubasi menunjukkan perbedaan yang sangat nyata terhadap nilai P-tersedia. P-tersedia tertinggi akibat pemberian kapur 2 minggu terdapat pada dosis $2 \mathrm{~g}$ yaitu 2,80 dan yang terendah pada dosis 3 g yaitu 2,08. Sedangkan pada inkubasi 4 minggu setelah pemberian kapur P-tersedia tertinggi terdapat pada dosis 4 g yaitu 2,80 dan yang terendah terlihat pada dosis $2 \mathrm{~g}$ yaitu 2,29. Pemberian kapur yang diinkubasi selama 6 minggu menunjukkan P-tersedia tertinggi pada dosis $4 \mathrm{~g}$ yaitu 3,53 dan yang terendah dapat terlihat pada dosis $2 \mathrm{~g}$ yaitu 2,80.

Pada inkubasi kapur 2 dan 4 minggu terlihat bahwa P-tersedia meningkat, tetapi lebih rendah dibandingkan sebelum diberi kapur 2,85, hal ini diduga karena $\mathrm{Ca}$ di dalam tanah sebelum diberi perlakuan ikut berinteraksi dengan P. Sebagaimana kita ketahui bahwa Ca juga dapat mengikat $\mathrm{P}$ sehingga membentuk $\mathrm{Ca}-\mathrm{P}$ didalam tanah. Kapur yang digunakan pada penelitian ini adalah jenis dolomit yang mana selain banyak mengadung unsur $\mathrm{Ca}$ juga mengandung $\mathrm{Mg}$ yang merupakan unsur basa yang dapat mengikat P. Selain faktor itu, diduga bahwa dengan inkubasi kapur 2 minggu maka $\mathrm{pH}$ sudah meningkat hingga mencapai netral, jadi pada $\mathrm{pH}$ ini kemungkinan $\mathrm{P}$ kembali terikat oleh $\mathrm{Ca}$. Hal ini sesuai dengan pernyataan Sutanto (2005), kebanyakan tanaman menghendaki $\mathrm{pH}$ yang agak masam dan pengapuran 
menjadikan $\mathrm{pH}$ mencapai 6 atau diatas 6 yang kemungkinan akan mengurangi ketersediaan $\mathrm{P}$ karena terikat oleh $\mathrm{Ca}$ membentuk Ca-P.

Pada inkubasi 6 minggu terlihat P-tersedia sudah meningkat dari sebelum diberi kapur hal ini diduga bahwa unsur Ca sudah tidak menjerap P dan $\mathrm{P}$ menjadi lebih tersedia. Unsur $\mathrm{Ca}$ lebih leluasa melepaskan $\mathrm{P}$ jika dibanding dengan $\mathrm{Al}$, maka dari itu pemberian kapur dengan waktu inkubasi 6 minggu dapat menaikkan P-tersedia dan melepas ikatan Ca. Pemberian dolomit pada tanah masam dapat meningkatkan ketersediaan hara dalam tanah seperti $\mathrm{Ca}$, $\mathrm{Mg}, \mathrm{P}$ dan lain-lain (Soepardi, 1983). Selain itu, pemberian kapur pada tanah masam memang dapat meningkatkan P-tersedia, disebabkan karena ion $\mathrm{OH}^{-}$yang dihasilkan dari bahan kapur merupakan anion yang dijerap secara spesifik. Anion ini mampu mengganti kedudukan $\mathrm{P}$ yang terikat oleh $\mathrm{Al}$ atau Fe (Iqbal, 2011).

Oleh karena itu, semakin lama inkubasi kapur maka P-tersedia semakin meningkat. Pada inkubasi 6 minggu P-tersedia sudah lebih meningkat dibandingkan sebelum diberikan kapur.

\section{Kapasitas Tukar Kation (KTK)}

Hasil analisis KTK pada tanah yang telah diberikan kapur dan diinkubasi dengan waktu dan dosis yang berbeda-beda selama 2, 4 dan 6 minggu. Hasil uji F pada Tabel analisis sidik ragam menunjukkan bahwa pemberian kapur berpengaruh terhadap KTK. Rata-rata KTK tanah setelah pemberian kapur yang diinkubai dalam waktu tertentu disajikan pada Tabel 8 .

Tabel 8. Rata-rata KTK $\left(\mathrm{cmol} \mathrm{kg}^{-1}\right)$ tanah setelah pemberian kapur dalam waktu 2, 4 dan 6 minggu

\begin{tabular}{cccc}
\hline \multirow{2}{*}{ Perlakuan } & \multicolumn{3}{c}{ Waktu Inkubasi } \\
\cline { 2 - 4 } & 2 Minggu & 4 Minggu & $6 \mathrm{Minggu}$ \\
K1 $(2 \mathrm{~g})$ & $16,05(\mathrm{a})$ & $16,75(\mathrm{~b})$ & $17,35(\mathrm{a})$ \\
K2 $(3 \mathrm{~g})$ & $15,83(\mathrm{a})$ & $18,45(\mathrm{c})$ & $21,33(\mathrm{~b})$ \\
K3 $(4 \mathrm{~g})$ & $17,68(\mathrm{~b})$ & $15,62(\mathrm{a})$ & $22,20(\mathrm{bc})$ \\
K4 $(5 \mathrm{~g})$ & $17,58(\mathrm{~b})$ & $16,88(\mathrm{~b})$ & $23,40(\mathrm{c})$ \\
\hline BNT 0,05 & 1,17 & 0,76 & 1,73 \\
\hline
\end{tabular}

Keterangan: Angka rata-rata yang diikuti oleh huruf yang sama tidak berbeda nyata pada uji BNT 0,05

Berdasarkan uji F, terlihat bahwa pemberian kapur setelah 2, 4 dan 6 minggu inkubasi menunjukkan perbedaan yang sangat nyata terhadap nilai KTK. Kapasitas Tukar Kation tertinggi akibat pemberian kapur 2 minggu terdapat pada dosis 4 g yaitu 17,68. Kapasitas Tukar Kation meningkat sebesar 2,08 dari jumlah KTK awal 15,60 dan yang terendah pada dosis 3 g yaitu 15,83, tetapi masih meningkat dibandingkan KTK awal yaitu sebesar 0,23. Sedangkan pada inkubasi 4 minggu setelah pemberian kapur KTK tertinggi terdapat pada dosis 3 g yaitu 18,45. Kapasitas Tukar Kation meningkat sebesar 2,85 dari jumlah KTK awal dan yang terendah terlihat pada dosis $4 \mathrm{~g}$ yaitu 15,62, dan masih meningkat dibandingkan dengan KTK awal yaitu sebesar 0,02. Pemberian kapur yang di inkubasi selama 6 minggu menunjukkan KTK tertinggi pada dosis 5 g yaitu 23,40. Kapasitas Tukar Kation meningkat sebesar 7,8 dari KTK awal dan yang terendah dapat terlihat pada dosis 2 g yaitu 17,35, tetapi masih meningkat dibandingkan KTK awal yaitu sebesar 1,75.

Menurut Kamprath dan Foy (1997), pemberian kapur pada tanah masam juga mempunyai kaitan dengan perbaikan terhadap KTK efektif dan retensi kation. Kapasitas Tukar Kation yang tergantung $\mathrm{pH}$ dari tanah masam berasosiasi dengan ionisasi $\mathrm{H}^{+}$dari oksida-oksida hidrolisis $\mathrm{Fe}$ dan $\mathrm{Al}$ dan hidrolisis ion-ion logam trivalent yang diikat oleh bahan organik. Oleh karena itu jika tanah masam dikapur, KTK efektifnya meningkat.

Sebagaimana kita ketahui bahwa pemberian kapur dapat meningkatkan $\mathrm{pH}$ tanah. Pada tanah-tanah yang bermuatan tergantung dengan $\mathrm{pH}$, maka KTK akan meningkat dengan 
pengapuran. Dengan demikian jelas bahwa pengapuran akan mempengaruhi KTK tanah (Hakim et al., 1986).

Oleh karena itu, semakin lama inkubasi kapur maka KTK semakin meningkat. Waktu inkubasi 6 minggu merupakan waktu yang tepat untuk menaikkan KTK dibanding inkubasi 2 dan 4 minggu.

\section{Al-dd}

Hasil analisis Al-dd pada tanah yang telah diberikan kapur dan diinkubasi dengan waktu dan dosis yang berbeda-beda selama 2, 4 dan 6 minggu. Rata-rata Al-dd tanah setelah pemberian kapur yang diinkubasi dalam waktu tertentu disajikan pada Tabel 9.

Tabel 9. Rata-rata Al-dd $\left(\mathrm{cmol} \mathrm{kg}^{-1}\right)$ tanah setelah pemberian kapur dalam waktu 2, 4 dan 6 minggu

\begin{tabular}{cccc}
\hline \multirow{2}{*}{ Perlakuan } & \multicolumn{3}{c}{ Waktu Inkubasi } \\
\cline { 2 - 4 } & 2 Minggu & 4 Minggu & 6 Minggu \\
\hline K1 $(2 \mathrm{~g})$ & tu & tu & tu \\
K2 $(3 \mathrm{~g})$ & tu & tu & tu \\
K3 $(4 \mathrm{~g})$ & tu & tu & tu \\
K4 $(5 \mathrm{~g})$ & tu & tu & tu \\
\hline
\end{tabular}

Keterangan: tu $=$ tidak terukur

Berdasarkan hasil analisis laboratorium, terlihat bahwa pemberian kapur setelah 2, 4 dan 6 minggu inkubasi menunjukkan perbedaan yang sangat nyata terhadap nilai Al-dd sehingga kadar Al-dd tidak dapat terukur. Kadar Al-dd awal sebelum diberikan kapur adalah sebesar $1,00 \mathrm{cmol} \mathrm{kg}^{-1}$. Jadi, setelah diberikan kapur maka kadar Al-dd nya berkurang hingga tak terukur.

Kapur dapat menggantikan dan mengendapkan Al yang telah diikat kuat dalam tanah masam. Sims (1986) dalam Indrasari dan Syukur (2006) mengatakan bahwa, $\mathrm{Al}^{3+}$ yang berasal dari larutan tanah akan bereaksi dengan $\mathrm{OH}^{-}$dari hasil reaksi bahan kapur sehingga membentuk endapan $\mathrm{Al}(\mathrm{OH})_{3}$. Oleh karena itu, pemberian bahan kapur mengakibatkan pengendapan $\mathrm{Al}$ dalam bentuk $\mathrm{Al}(\mathrm{OH})_{3}$ dan pada saat yang sama $\mathrm{pH}$ akan meningkat. Dengan demikian keracunan $\mathrm{Al}$ dapat teratasi sehingga pertumbuhan akar tanaman akan baik. Hal itu juga sama dengan pendapat Hasanudin et al. (2007) yang menyatakan bahwa kapur dapat menetralisir $\mathrm{Al}$ melalui ion $\mathrm{OH}^{-}$membentuk $\mathrm{Al}(\mathrm{OH})_{3}$ tidak aktif yang dihasilkan dari pelepasan $\mathrm{CO}_{3}{ }^{2-}$ yang selanjutnya $\mathrm{Al}$ menjadi tidak larut dan $\mathrm{Al}-\mathrm{dd}$ semakin berkurang.

Pada waktu inkubasi 2 minggu, kadar Al-dd sudah hilang dan tidak dapat diukur. Oleh karena itu, untuk mengurangi kadar Al-dd cukup dengan 2 minggu inkubasi kapur saja dan tanah akan terbebas dari unsur yang dapat meracuni tanaman dan menghambat pertumbuhan tanaman sehingga unsur-unsur hara didalam tanah menjadi lebih banyak yang tersedia dan dapat diserap oleh tanaman.

\section{Abu Sekam pH Tanah}

Hasil analisis $\mathrm{pH}$ pada tanah yang telah diberikan abu sekam dan diinkubasi dengan waktu dan dosis yang berbeda-beda selama 2, 4 dan 6 minggu. Hasil uji F pada Tabel analisis sidik ragam menunjukkan bahwa pemberian abu sekam berpengaruh terhadap $\mathrm{pH}$. Rata-rata $\mathrm{pH}$ tanah setelah pemberian abu sekam yang diinkubasi dalam waktu tertentu disajikan pada Tabel 10. 
Tabel 10. Rata-rata pH tanah setelah pemberian abu sekam dalam waktu 2, 4 dan 6 minggu

\begin{tabular}{cccc}
\hline \multirow{2}{*}{ Perlakuan } & \multicolumn{3}{c}{ Waktu Inkubasi } \\
\cline { 2 - 4 } & 2 Minggu & 4 Minggu & 6 Minggu \\
\hline A1 $(5 \mathrm{~g})$ & $5,66(\mathrm{a})$ & $6,12(\mathrm{c})$ & $5,64(\mathrm{~b})$ \\
A2 $(7,5 \mathrm{~g})$ & $6,00(\mathrm{c})$ & $5,90(\mathrm{~b})$ & $5,75(\mathrm{c})$ \\
A3 $(10 \mathrm{~g})$ & $5,74(\mathrm{~b})$ & $5,80(\mathrm{~b})$ & $5,63(\mathrm{ab})$ \\
A4 $(12,5 \mathrm{~g})$ & $5,65(\mathrm{a})$ & $5,66(\mathrm{a})$ & $5,59(\mathrm{a})$ \\
\hline BNT 0,05 & 0,07 & 0,06 & 0,04 \\
\hline
\end{tabular}

Keterangan: Angka rata-rata yang diikuti oleh huruf yang sama tidak berbeda nyata pada uji BNT 0,05

Berdasarkan uji $\mathrm{F}$, terlihat bahwa pemberian abu sekam setelah 2, 4 dan 6 minggu inkubasi menunjukkan perbedaan yang sangat nyata terhadap nilai $\mathrm{pH}$. Kemasaman $(\mathrm{pH})$ tertinggi akibat pemberian abu sekam 2 minggu terdapat pada dosis 7,5 g yaitu 6,00. Kemasaman $(\mathrm{pH})$ meningkat sebesar 0,65 dari $\mathrm{pH}$ awal 5,35 dan yang terendah pada dosis $12,5 \mathrm{~g}$ yaitu 5,65, tetapi masih meningkat dibandingkan $\mathrm{pH}$ awal yaitu sebesar 0,3 . Sedangkan pada inkubasi 4 minggu setelah pemberian abu sekam $\mathrm{pH}$ tertinggi terdapat pada dosis $5 \mathrm{~g}$ yaitu 6,12. Kemasaman $(\mathrm{pH})$ meningkat sebesar 0,77 dari $\mathrm{pH}$ awal dan yang terendah terlihat pada dosis 12,5 g yaitu 5,66, dan masih meningkat dibandingkan dengan $\mathrm{pH}$ awal yaitu sebesar 0,31. Pemberian abu sekam yang diinkubasi selama 6 minggu menunjukkan $\mathrm{pH}$ tertinggi pada dosis 7,5 g yaitu 5,75. Kemasaman $(\mathrm{pH})$ meningkat sebesar 0,4 dari $\mathrm{pH}$ awal dan yang terendah dapat terlihat pada dosis $12,5 \mathrm{~g}$ yaitu 5,59, tetapi masih meningkat dibandingkan $\mathrm{pH}$ awal yaitu sebesar 0,24 .

Abu sekam juga sangat memberikan perubahan yang nyata pada kenaikan $\mathrm{pH}$ tanah, abu sekam yang mengandung silikat yang tinggi mampu menaikkan $\mathrm{pH}$ tanah karena silikat dapat menyumbangkan anion $\mathrm{OH}^{-}$sehingga dapat menetralkan asam dan $\mathrm{pH}$ tanah pun meningkat. Kandungan silikat yang terkandung pada abu sekam yang digunakan adalah sebesar 65,68\%. Namun kandungan silikat ini tentunya berbeda-beda antara abu sekam yang satu dengan yang lainnya tergantung tingkat pembakarannya. Sesuai dengan yang dinyatakan oleh Ilyas et al. (2000), bahwa silikat dari abu sekam mampu melepaskan anion $\mathrm{OH}^{-}$ke dalam larutan sehingga $\mathrm{pH}$ meningkat.

Inkubasi 4 minggu merupakan waktu yang tepat untuk menaikkan $\mathrm{pH}$ dibandingkan waktu 2 atau 6 minggu. Pada waktu 6 minggu pH kembali turun diduga karena $\mathrm{pH}$ akibat pemberian abu sekam sudah maksimal pada saat 4 minggu inkubasi dan tidak dapat bereaksi lebih dari itu.

\section{P-tersedia}

Hasil analisis P-tersedia pada tanah yang telah diberikan abu sekam dan diinkubasi dengan waktu dan dosis yang berbeda-beda selama 2, 4 dan 6 minggu. Hasil uji F pada Tabel analisis sidik ragam menunjukkan bahwa pemberian abu sekam berpengaruh terhadap Ptersedia. Rata-rata P-tersedia tanah setelah pemberian abu sekam yang diinkubasi dalam waktu tertentu disajikan pada Tabel 11.

Berdasarkan uji $\mathrm{F}$, terlihat bahwa pemberian abu sekam setelah 2, 4 dan 6 minggu inkubasi menunjukkan perbedaan yang sangat nyata terhadap nilai P-tersedia. P-tersedia tertinggi akibat pemberian abu sekam 2 minggu terdapat pada dosis $10 \mathrm{~g}$ dan $12,5 \mathrm{~g}$ yaitu 2,74 dan yang terendah pada dosis $5 \mathrm{~g}$ yaitu 2,39. Sedangkan pada inkubasi 4 minggu setelah pemberian abu sekam P-tersedia tertinggi terdapat pada dosis 7,5 yaitu 3,27 dan yang terendah terlihat pada dosis $5 \mathrm{~g}$ yaitu 2,41. Pemberian abu sekam yang di inkubasi selama 6 minggu menunjukkan P-tersedia tertinggi pada dosis 7,5 g yaitu 3,26 dan yang terendah dapat terlihat pada dosis 5 g yaitu 2,46. 
Tabel 11. Rata-rata P-tersedia $\left(\mathrm{mg} \mathrm{kg}^{-1}\right)$ setelah pemberian abu sekam dalam waktu 2, 4 dan 6 minggu

\begin{tabular}{cccc}
\hline \multirow{2}{*}{ Perlakuan } & \multicolumn{3}{c}{ Waktu Inkubasi } \\
\cline { 2 - 4 } & 2 Minggu & 4 Minggu & 6 Minggu \\
\hline A1 $(5 \mathrm{~g})$ & $2,39(\mathrm{a})$ & $2,41(\mathrm{a})$ & $2,46(\mathrm{a})$ \\
A2 $(7,5 \mathrm{~g})$ & $2,72(\mathrm{~b})$ & $3,27(\mathrm{~b})$ & $3,26(\mathrm{~b})$ \\
A3 $(10 \mathrm{~g})$ & $2,74(\mathrm{~b})$ & $2,58(\mathrm{a})$ & $3,21(\mathrm{~b})$ \\
A4 $(12,5 \mathrm{~g})$ & $2,74(\mathrm{~b})$ & $2,49(\mathrm{a})$ & $3,21(\mathrm{~b})$ \\
\hline BNT 0,05 & 0,15 & 0,23 & 0,23 \\
\hline
\end{tabular}

Keterangan: Angka rata-rata yang diikuti oleh huruf yang sama tidak berbeda nyata pada uji BNT 0,05

Peningkatan P-tersedia terlihat jelas pada inkubasi ke 6 minggu. Pada inkubasi 2 dan 4 minggu P-tersedia lebih rendah dibandingkan sebelum diberi abu sekam 2,85, hal ini diduga karena abu sekam juga mengadung unsur $\mathrm{Ca}$ yang merupakan kation basa yang dapat mengikat $\mathrm{P}$, unsur tersebut terdapat dalam jumlah yang banyak sehingga kembali dapat mengikat $\mathrm{P}$ yang sudah tersedia sebelum diberikan perlakuan.

Pada inkubasi 6 minggu terlihat P-tersedia sudah meningkat dari sebelum diberi abu sekam hal ini diduga bahwa unsur $\mathrm{Ca}$ yang ada didalam abu sekam sudah tidak menjerap $\mathrm{P}$ dan P menjadi lebih tersedia. Unsur basa seperti Ca lebih leluasa melepaskan P jika dibanding dengan Al, karena ikatannya yang tidak sekuat Al. Selain itu juga karena silikat dari abu sekam membutuhkan waktu untuk bereaksi dalam tanah, sehingga reaksi baru sempuna setelah melewati periode inkubasi 2 sampai 4 minggu (Ilyas et al., 2000).

Menurut Paiman (1999), penambahan abu sekam dapat meningkatkan kadar P tanah. Abu sekam padi mengandung banyak unsur silika yang berpengaruh nyata terhadap pelepasan $\mathrm{P}$ terjerap. Ion silikat mempunyai kemampuan lebih besar untuk berikatan, sehingga silikat mampu mengganti kedudukan $\mathrm{P}$ dalam menempati tapak jerapan. Mekanisme pemberian Si yang efektif dapat diukur dari penambahan $\mathrm{P}$ tersedia yang dihasilkan dari pertukaran $\mathrm{Si}$ dengan $\mathrm{P}$ yang diadsorpsi oleh sesquioksida (Alridiwirsah et al., 2011).

Oleh karena itu, semakin lama inkubasi abu sekam maka P-tersedia semakin meningkat. Pada inkubasi 6 minggu P-tersedia sudah lebih meningkat dibandingkan inkubasi 2 dan 4 minggu.

\section{Kapasitas Tukar Kation (KTK)}

Hasil analisis KTK pada tanah yang telah diberikan abu sekam dan diinkubasi dengan waktu dan dosis yang berbeda-beda selama 2, 4 dan 6 minggu. Hasil uji F pada Tabel analisis sidik ragam menunjukkan bahwa pemberian abu sekam berpengaruh terhadap KTK. Rata-rata KTK tanah setelah pemberian abu sekam yang diinkubasi dalam waktu tertentu disajikan pada Tabel 12.

Berdasarkan uji $\mathrm{F}$, terlihat bahwa pemberian abu sekam setelah 2 dan 4 minggu inkubasi berbeda nyata terhadap nilai KTK. Sedangkan pada 6 minggu inkubasi berpengaruh sangat nyata terhadap nilai KTK. Kapasitas Tukar Kation tertinggi akibat pemberian abu sekam 2 minggu terdapat pada dosis $10 \mathrm{~g}$ yaitu 17,78. Kapasitas Tukar Kation meningkat sebesar 2,18 dari KTK awal 15,60 dan yang terendah pada dosis 12,5 g yaitu 16,75, tetapi masih meningkat dibandingkan KTK awal yaitu sebesar 1,15. Sedangkan pada inkubasi 4 minggu setelah pemberian abu sekam KTK tertinggi terdapat pada dosis $10 \mathrm{~g}$ yaitu 18,63. Kapasitas Tukar Kation meningkat sebesar 3,03 dari KTK awal dan yang terendah pada dosis 5 g yaitu 16,75, dan masih meningkat dibandingkan dengan KTK awal yaitu sebesar 1,15. Pemberian abu sekam yang di inkubasi selama 6 minggu menunjukan KTK tertinggi pada dosis $10 \mathrm{~g}$ yaitu 21,88. KTK meningkat sebesar 6,28 dari KTK awal dan yang terendah dapat terlihat pada dosis $5 \mathrm{~g}$ yaitu 17,50, tetapi masih meningkat dibandingkan KTK awal yaitu sebesar 1,9. 
Tabel 12. Rata-rata KTK ( $\left.\mathrm{cmol} \mathrm{kg}^{-1}\right)$ tanah setelah pemberian abu sekam dalam waktu 2, 4 dan 6 minggu

\begin{tabular}{cccc}
\hline \multirow{2}{*}{ Perlakuan } & \multicolumn{3}{c}{ Waktu Inkubasi } \\
\cline { 2 - 4 } & 2 Minggu & 4 Minggu & 6 Minggu \\
\hline A1 $(5 \mathrm{~g})$ & $17,15(\mathrm{ab})$ & $16,75(\mathrm{a})$ & $17,50(\mathrm{a})$ \\
A2 $(7,5 \mathrm{~g})$ & $16,90(\mathrm{a})$ & $17,68(\mathrm{ab})$ & $20,75(\mathrm{~b})$ \\
A3 $(10 \mathrm{~g})$ & $17,78(\mathrm{~b})$ & $18,63(\mathrm{~b})$ & $21,88(\mathrm{c})$ \\
A4 $(12,5 \mathrm{~g})$ & $16,75(\mathrm{a})$ & $17,58(\mathrm{ab})$ & $21,08(\mathrm{bc})$ \\
\hline BNT 0,05 & 0,06 & 1,17 & 0,81 \\
\hline
\end{tabular}

Keterangan: Angka rata-rata yang diikuti oleh huruf yang sama tidak berbeda nyata pada uji BNT 0,05

Abu sekam sebagai salah satu bahan organik juga mempengaruhi KTK tanah, abu sekam mengandung kalsium $(\mathrm{Ca})$ sebagai kation basa yang dapat meningkatkan KTK tanah. Dari peningkatan unsur KTK ini, maka tanaman semakin mudah dalam menyerap unsur hara dari tanah. Sehingga peran bahan organik yaitu abu sekam memberikan kontribusi yang nyata terhadap KTK tanah. Stevenson (1982) dalam penelitiannya menyataka bahwa sekitar 20-70 $\%$ kapasitas pertukaran tanah pada umumnya bersumber pada koloid humus, sehingga terdapat korelasi antara bahan organik dengan KTK tanah. Menurut analisis Bell dan Simmons (1997), bahwa kandungan silika dari abu sekam dapat mencapai $69 \%$. Selain itu, pengaruh bahan organik mempunyai daya jerap kation yang lebih besar daripada koloid liat. Oleh karena itu, semakin tinggi bahan organik suatu tanah tanah maka makin tinggi pula KTK nya (Rosmarkam dan Yuwono, 2002). Oleh karena itu, semakin lama inkubasi abu sekam maka KTK semakin meningkat. Waktu inkubasi 6 minggu merupakan waktu paling tepat untuk menaikkan KTK.

\section{Al-dd}

Hasil analisis Al-dd pada tanah yang telah diberikan abu sekam dan diinkubasi dengan waktu dan dosis yang berbeda-beda selama 2, 4 dan 6 minggu. Rata-rata Al-dd tanah setelah pemberian abu sekam yang diinkubasi dalam waktu tertentu disajikan pada Tabel 13.

Tabel 13. Rata-rata Al-dd $\left(\mathrm{cmol} \mathrm{kg}^{-1}\right)$ tanah setelah pemberian abu sekam dalam waktu 2, 4 dan 6 minggu

\begin{tabular}{cccc}
\hline \multirow{2}{*}{ Perlakuan } & \multicolumn{3}{c}{ Waktu Inkubasi } \\
\cline { 2 - 4 } & 2 Minggu & 4 Minggu & 6 Minggu \\
\hline A1 $(5 \mathrm{~g})$ & tu & tu & tu \\
A2 $(7,5 \mathrm{~g})$ & tu & tu & tu \\
A3 $(10 \mathrm{~g})$ & tu & tu & tu \\
A4 $(12,5 \mathrm{~g})$ & tu & tu & tu \\
\hline
\end{tabular}

Keterangan: tu $=$ tidak terukur

Berdasarkan hasil analisis laboratorium, terlihat bahwa pemberian abu sekam setelah 2 minggu inkubasi menunjukkan perbedaan yang sangat nyata terhadap nilai Al-dd sehingga kadar Al-dd tidak dapat terukur. Kadar Al-dd awal sebelum diberikan abu sekam adalah sebesar 1,00 $\mathrm{cmol} \mathrm{kg}^{-1}$. Jadi, setelah diberikan abu sekam maka kadar Al-dd nya berkurang hingga tak terukur.

Pemberian abu sekam bermanfaat untuk peningkatan $\mathrm{pH}$ tanah sehingga unsur-unsur yang terjerap akan mudah terlepas dan dapat diserap oleh tanaman. Kelarutan oksida-oksida atau hidroksida $\mathrm{Fe}$ dan $\mathrm{Al}$ secara langsung bergantung pada konsentrasi ion hidroksil $(\mathrm{OH})$ dan kelarutannya menurun jika $\mathrm{pH}$ meningkat. Kelarutan Fe-P, Al-P sangat bergantung pada $\mathrm{pH}$ (Alridiwirsah et al., 2011). 
Pada waktu inkubasi 2 minggu, kadar Al-dd sudah hilang dan tidak dapat diukur. Oleh karena itu, untuk mengurangi kadar Al-dd cukup dengan 2 minggu inkubasi abu sekam saja dan tanah akan terbebas dari unsur yang dapat meracuni tanaman dan menghambat pertumbuhan tanaman sehingga unsur-unsur hara didalam tanah menjadi lebih banyak yang tersedia dan dapat diserap oleh tanaman.

\section{KESIMPULAN DAN SARAN}

Pemberian kapur dolomit dan abu sekam pada Ultisol menunjukkan perbedaan yang sangat nyata pada $\mathrm{pH}$, P-tersedia, KTK dan Al-dd. Waktu inkubasi yang tepat untuk menaikkan $\mathrm{pH}$, P-tersedia dan KTK setelah pemberian kapur adalah selama 6 minggu, sedangkan waktu inkubasi yang tepat untuk menurunkan Al-dd adalah selama 2 minggu. Waktu inkubasi yang tepat untuk menaikkan P-tersedia dan KTK setelah pemberian abu sekam adalah selama 6 minggu, sedangkan waktu inkubasi untuk menurunkan Al-dd adalah selama 2 minggu dan waktu untuk menaikkan $\mathrm{pH}$ adalah selama 4 minggu. Untuk mendapatkan gambaran yang lebih jelas terhadap sifat kimia Ultisol maka perlu dilakukan penelitin lebih lanjut dengan menggunakan tanaman, waktu inkubasi yang berbeda dan pada jenis tanah lainnya, interaksi antara kapur dan abu sekam agar memperoleh hasil yang lebih baik serta pengambilan sampel tanah secara merata atau mewakili ketika hendak menganalisis ke laboratorium.

\section{DAFTAR PUSTAKA}

Alridiwirsah, Asritanarni, M., Riko, R.A. dan Simamora. 2011. Pengaruh Abu Sekam Padi dan Pupuk Seprint terhadap Pertumbuhan dan Produksi Tanaman Semangka. Jurusan Agroekoteknologi Fakultas Pertanian UMSU Medan, Medan.

Bell, P.F. dan Simmons, T.F. 1997. Silicon Concentration of Biological Standards. Soil Science Society of America J., 61: 321-332.

Hakim, N., Nyakpa, M.Y., Lubis, A.M., Nugroho, S.G., Diha, M.A., Hong, G.B. dan Bailey, H.H. 1986. Dasar-Dasar Ilmu Tanah. Lampung. Universitas Lampung. hal. 488.

Hardjowigeno, S. 1992. Ilmu Tanah. Mediyatama Sarana Perkasa. Jakarta.

Ilyas, Syekhfani dan Prijono, S. 2000. Analisis Pemberian Limbah Pertanian Abu Sekam Sebagai Sumber Silikat pada Andisol dan Oxisol terhadap Pelepasan Fosfor Terjerap dengan Teknik Perunut. Risalah Pertemuan Ilmiah Penelitian dan Pengembangan Teknologi Isotop dan Radiasi. Malang.Direktorat Jendral Pendidikan Tinggi Departemen Pendidikan dan Kebudayaan. 1991. Jakarta.

Indrasari, A., Syukur. A. 2006. Pengaruh Pemberian Pupuk Kandang dan Unsur Hara Mikro terhadap Pertumbuhan Jagung pada Ultisol yang Dikapur. Jurnal Ilmu Tanah dan Lingkungan. Vol 6. hal. 116-123.

Iqbal, R. 2011. Pengaruh Pemberian Kapur CaCO3 terhadap Sifat Kimia Ultisol. Jurusan Budidaya Pertanian. Fakultas Pertanian Universitas Syiah Kuala. Banda Aceh.

Kamprath, EU., Foy CD. 1997. Interaksi Kapur-Pupuk Tanaman pada Tanah-Tanah Masam. dalam Engelstad O. P. (ed). Teknologi dan Penggunaan Pupuk. Edisi Ketiga. (terjemahan Goenadi G.H.) Gadjah Mada University. Press. hal. 132-227.

Kuswandi. 1993. Pengapuran Tanah Pertanian. Edisi Revisi. Yogyakarta: Kanisius.

Mengel, K. and E. A. Kirkby. 1987. Principles of Plant Nutrition. International Potash Institute. Switzerland.

Paiman, A. 1999. Efek Pemberian berbagai Amelioran dan Abu terhadap Pertumbuhan dan Produksi Kedelai pada Lahan Gambut. Jurnal Agronomi 10 (2):85-92. 
Raihan, S., Hairunsyah, A. Noor, dan Y. Raihana. 2005. Peranan Beberapa Macam Bahan Organik dan Pupuk Kalium terhadap Pertumbuhan dan Hasil Jagung di Lahan Kering. http://www.google.com/scholar, diakses pada tanggal 18 Maret 2017.

Rosmarkam dan Yuwono. 2002. Ilmu Kesuburan Tanah. Kanisius. Jakarta.

Sims, J. T. 1986. Soil pH Effect on the Distribution and Plant Availability of Manganese, Copper and Zinc. Soil Sci Soc Am J. Vol 50 : 367-373.

Soepardi, G. 1983. Sifat dan Ciri Tanah. Departemen Ilmu Tanah Fakultas Pertanian IPB. Bogor.

Susanti, E. 1994. Penurunan Kadar Best (Fe) dengan Abu Sekam Padi sebagai Media Penukar Ion. Skripsi UPN “ Veteran “ Jawa Timur.

Sutanto, R. 2005. Dasar-Dasar Ilmu Tanah. Penerbit Kanisius (Anggota IKPI). Yogyakarta.

Sri Adiningsih, J. dan Mulyadi. 1993. Alternatif Teknik Rehabilitasi dan Pemanfaatan Lahan Alang-Alang. hal. 29-50. dalam S. Sukmana, Suwardjo, J. Sri Adiningsih, H. Subagjo, H. Suhardjo, Y. Prawirasumantri (Ed.). Pemanfaatan Lahan Alang-Alang untuk Usaha Tani Berkelanjutan. Prosiding Seminar Lahan Alang-alang. Bogor. 